
\title{
Research S Surate \\ Factors Associated with COVID-19 Infection among a National Population of Individuals with Schizophrenia in the United States
}

Joshua N Liberman ( $\boldsymbol{\sim}$ j.liberman@healthanalytics.com )

Health Analytics, LLC

Jacqueline Pesa

Janssen Scientific Affairs

Mary Pat Petrillo

Janssen Scientific Affairs

Charles Ruetsch

Health Analytics, LLC

\section{Research Article}

Keywords: COVID-19, schizophrenia, risk factors, social determinants

Posted Date: February 8th, 2022

DOI: https://doi.org/10.21203/rs.3.rs-1167919/v1

License: (9) (1) This work is licensed under a Creative Commons Attribution 4.0 International License. Read Full License 


\section{Abstract}

Background: Schizophrenia is a serious mental illness and individuals with schizophrenia are a particularly vulnerable and often under-served population.

Methods: This research sought to evaluate the factors associated with risk of COVID-19 infection among a representative population of individuals with schizophrenia in the United States. This study was a retrospective cohort analysis of medical and pharmacy claims among a population-based sample of 493,796 individuals residing in the United States with schizophrenia or schizoaffective disorder, between January 1, 2019 and June 30, 2020. A confirmed diagnosis of COVID-19 infection by September 30, 2020 was regressed on demographics, social determinants (measured at the county level, with each measure categorized into quintiles), comorbidity, and pre-pandemic (December 2019 - February 2020) healthcare utilization characteristics.

Results: A total of 35,249 (7.1\%) individuals were diagnosed with COVID-19. Elevated odds of COVID-19 infection were associated with age groups above 40 years (compared to 18-29 years) increasing consistently from 40-49 years (OR: 1.16) to 80+ years (OR:5.92), male sex (OR: 1.08), Medicaid (OR: 2.17) or Medicare (OR: 1.23) insurance, African American race (OR: 1.42 comparing the highest and lowest quintile), Hispanic ethnicity (OR: 1.23, comparing highest to lowest quintile), and higher Charlson Comorbidity Index, increasing from scores of 1-2 (OR: 1.84), 3-4 (OR: 2.53), to 5+ (OR: 2.76). Select psychiatric comorbidities (depressive disorder, adjustment disorder, bipolar disorder, anxiety, and sleep-wake disorder) were associated with elevated odds of infection, while alcohol use disorder and PTSD were associated with lower odds. A pre-pandemic psychiatry (OR:0.56) or community mental health center (OR:0.55) visit were associated with lower odds as was antipsychotic treatment: long-acting injectable antipsychotic (OR: 0.72) and oral antipsychotic (OR: 0.62).

Conclusions: Individuals with a diagnosis of schizophrenia were at substantial risk of COVID-19 infection, risk that was elevated for older adults and select social determinants, specifically African American race and Hispanic ethnicity. Individuals actively engaged in psychiatric treatment had substantially lower likelihood of infection.

\section{Introduction}

Schizophrenia is a serious mental illness characterized by symptoms of psychosis (e.g., hallucinations, delusions, and thought disorder), negative symptoms (e.g., social and emotional withdrawal), and cognitive dysfunction (e.g., difficulties with attention, memory, concentration). Schizophrenia can be a disabling condition, with $50 \%$ of those individuals who receive a diagnosis having long-term psychiatric problems and $20 \%$ having chronic symptoms and disability[1]. In the United States, the estimated prevalence of diagnosed schizophrenia is between $0.4 \%$ and $0.5 \%$ [2-4], affecting an estimated 1 million adults.

Due to the nature of the condition, individuals with schizophrenia are a particularly vulnerable and often underserved population[5]. Individuals with schizophrenia have higher rates of unemployment, are more likely insured via Medicaid, have lower socioeconomic status, lower levels of education, and reside in high risk, poverty environments[6].

These conditions and situations can be important determinants of health and as important, appear to increase both the risk of COVID-19 infection and the risk of severe morbidity and mortality following infection. Recently published research indicates that individuals with any serious mental illness, including schizophrenia, have 1.5 
times the risk of COVID-19 infection[7], due at least in part to cognitive impairment, lower awareness of risk, and challenges with infection control[2]. Once infected, individuals with schizophrenia have substantially higher rates of hospitalization and mortality[7-8]. In a consecutive case series of 7,348 individuals with a positive COVID-19 laboratory test, Nemani, et al.[9] reported that history of a schizophrenia spectrum disorder diagnosis was associated with an increased odds of mortality (OR: $2.67 ; 95 \% \mathrm{Cl}: 1.48-4.80$ ), an association not reported for either mood disorders or anxiety.

The current research study builds on this preliminary evidence by evaluating the factors associated with risk of COVID-19 infection among a large, representative population of individuals with schizophrenia in the United States.

\section{Methods}

This study was a retrospective cohort study of 493,796 individuals who entered the COVID-19 pandemic with a diagnosis of schizophrenia. The study compared the population of individuals who did and did not receive a COVID-19 diagnosis by September 30, 2020. The study protocol was approved by the Advarra Institutional Review Board.

\section{Data Sources and Management}

Individuals were identified and selected from medical and pharmacy claims Real-World Data licensed from Decision Resources Group. In addition, these claims data were used to measure healthcare resource utilization. Social determinants of health were measured at the county level from the Area Health Resources File available from the Department of Health and Human Services (www.data.hrsa.gov/topics/health-workforce/ahrf). Each individual was assigned to a county based on a combination of their 3-digit ZIP code, linked to the 5-digit ZIP code associated with their provider, assigned hierarchically beginning with the primary care provider, then the mental health care provider or clinic.

\section{Identification and Selection of Study Participants}

The study period was January 1, 2019 through September 30, 2020. Eligible individuals met each of the following criteria: diagnosis of schizophrenia or schizoaffective disorder (ICD-10-CM: F20.x, F25.x) defined by two or more outpatient claims (or one inpatient claim) between January 1, 2019 and June 30, 2020, 18 years of age or older as of January 1, 2019, a resident of the 50 United States or District of Columbia, and ongoing use of healthcare services as measured by at least one medical or pharmacy claim between each of January 1 and June 30, 2019; January 1 and June 30, 2020; and July 1 to September 30, 2020.

The index date for the pandemic was defined as March 1,2020. The outcome measure, COVID-19 infection, was defined by ICD-10-CM B97.29 (from January 1 - March 31, 2020) and by U07.1 (from April 1 through September 30, 2020).

\section{Statistical Analysis}


Covariates included demographic characteristics (age and gender), insurance type (Medicare, Medicaid, commercial, or VA/other), medical comorbidity measured by the Charlson Comorbidity Index[10] psychiatric comorbidities, health care resource utilization prior to the pandemic, and social determinants of health.

Psychiatric comorbidities included anxiety (F41.x), adjustment disorders (F43.2x), bipolar depression (F30.x, F31.x), obsessive-compulsive disorder (F42.x), PTSD (F43.1x), sleep-wake disorders (G47.x), alcohol and substance use disorders (F10.x - F19.x, F32.x, F33.x, F34.1), and depressive disorders (F32.x, F33.x). Health care resource utilization was measured in the three-month period prior to March 1, 2020. Outpatient care was measured by an all-cause psychiatry office visit, psychotherapy session, or community mental health clinic visit. Acute care utilization was measured by partial-day hospitalization or schizophrenia-specific emergency department or inpatient hospitalization. Medication treatment was measured as at least one claim for an oral or long-acting injectable (LAl) antipsychotic. Social determinants of health, measured at the assigned county of residence included population density (residents per sq. mile as of 2010), median household income, education (\% graduated high school), race (\% African American/black, \% white, \% Asian), and ethnicity (\% Hispanic).

Frequencies and percentages were calculated for categorical variables: significance testing by chi-square test. Means and standard deviations for continuous variables: significance testing by two-sided T-test for mean. Adjusted odds ratios (OR) and 95\% confidence intervals (CI) were derived from a multivariate logistic regression modeling of COVID-19 infection (dependent variable). The threshold for significance was set at 0.05. All analyses were performed with SAS software, v9.4, SAS Institute Inc., Cary, NC, USA.

\section{Results}

The eligible study population of 493,796 individuals (Table 1 ) included residents of all 50 U.S. states and the District of Columbia, more males (55.2\% vs. 44.8\%), with an average age of 50.1 (SD: 15.5) years, and individuals primarily insured by Medicaid (68.2\%) followed by Medicare (18.2\%) and commercial plans (16.8\%). The average Charlson Comorbidity Index score was 1.3 (SD: 1.9) and the most common diagnosed psychiatric comorbidity was anxiety disorder, affecting $31.5 \%$ of the population, followed by depressive disorders (29.7\%), bipolar depression (24.5\%), and sleep-wake disorders (16.7\%). The most recent schizophrenia-associated diagnosis was unspecified schizophrenia (29.1\%), bipolar-type schizoaffective disorder (25.5\%), unspecified schizoaffective disorder (14.5\%), paranoid schizophrenia (13.6\%), and depressive type schizoaffective disorder (10.8\%).

In the three months prior to March 1, 2020, an estimated $24.8 \%$ and $6.5 \%$ of the population had a claim for an oral antipsychotic medication and an LAI antipsychotic, respectively. A total of $8.9 \%$ had a community mental health center visit, $8.3 \%$ had a psychiatry office visit, and $6.1 \%$ had psychotherapy session. Among the countylevel social determinants of health, the average population density was 3,664 residents per square mile (SD: $9,914)$, the average median household income was $\$ 60,400$ (SD: $\$ 15,800)$, with an average high school graduation rate of $87.0 \%$ (SD: 5.3\%). The average county had 16.0\% African American, 59.1\% white, 16.4\% Hispanic, and $5.7 \%$ Asian residents. (Table 2)

By September 30, 2020, a total of 35,249 (7.1\%) individuals had received a COVID-19 diagnosis. Individuals diagnosed with COVID-19 were more likely to be female (50.7\% vs. 44.3\%), older (59.9 vs. 49.4 years of age), more likely insured by Medicaid ( $80.7 \%$ vs. $67.2 \%)$, and less likely insured by a commercial plan (5.0\% vs. $14.1 \%)$ or Medicare (14.2\% vs. 18.5\%). Further, those with a COVID-19 diagnosis resided in counties with slightly higher income (\$61.24K vs. $\$ 60.37 \mathrm{~K})$, lower rates of education (86.5\% vs. 87.1\%), and lower population density $(3,550$ 
vs. 3,673). Race and ethnicity also varied by county among those with and without a COVID-19 diagnosis, with positive cases residing in counties with a higher percent African American (16.6\% vs. 16.0\%), Hispanic (18.1\% vs. $16.3 \%)$, and Asian (6.2\% vs. $5.7 \%$ ) residents. All comparisons were statistically significant.

COVID-19 positive individuals had higher Charlson Comorbidity Index (2.5 vs. 1.2) and were more likely to have anxiety disorder (42.3\% vs. $30.7 \%)$, depressive disorders (46.1\% vs. $28.4 \%)$, bipolar depression (31.4\% vs. $24.0 \%)$, sleep-wake disorders (24.4\% vs. 16.1\%), and adjustment disorders (5.5\% vs. 3.3\%). However, infected individuals were less likely to be diagnosed with alcohol use disorder (11.2\% vs. $12.1 \%)$ or post-traumatic stress disorder (7.0\% vs. $9.4 \%)$.

Pre-pandemic health care utilization also varied between those with and without a COVID-19 diagnosis. Individuals who received a diagnosis were substantially less likely to have a pre-pandemic visit to a psychiatrist (3.8\% vs. $8.7 \%)$, psychotherapist (3.0\% vs. $6.4 \%)$, or community mental health center (3.8\% vs. $9.2 \%)$ and to have pre-pandemic antipsychotic medication use: LAl antipsychotic (3.2\% vs. $6.8 \%)$, oral antipsychotic use (15.2\% vs. 25.5\%). All results were statistically significant (Table 2).

\section{Regression}

With the exception of sex, the associations above remained after adjustment for all other factors. (Table 3; Figure 1) After adjustment, the factors most strongly positively-associated with COVID-19 infection were age (80+ years OR: 5.92, 70-79 years: OR 4.44, compared to 18-29 years), Charlson Comorbidity Index (5+ OR: 2.76; 3-4: 2.53; 1-2: $1.84)$, percent African American residents in the county (highest $\left(5^{\text {th }}\right)$ quintile: OR: $1.42,4^{\text {th }}$ quintile: $1.26,3^{\text {rd }}$ quintile: OR: $1.39 ; 2^{\text {nd }}$ quintile: 1.20$)$, and select psychiatric comorbidities, with the strongest association with depressive disorder (OR: 1.45) followed by adjustment disorder (OR:1.29), anxiety (OR: 1.23), bipolar disorder (OR: 1.22), and sleep-wake disorder (OR:1.16). Factors strongly inversely-associated with COVID-19 infection were prepandemic utilization of healthcare services including a CMHC visit (OR: 0.55), psychiatry office visit (OR: 0.56), oral antipsychotic use (OR:0.62), or LAI use (OR: 0.72), PTSD (OR 0.79) or alcohol use disorder (OR: 0.86), and higher percentage of Asian residents in a county. (Table 3; Figure 1)

\section{Discussion}

By the end of September 2020, the estimated prevalence rate of COVID-19 infection among the study population was $7.3 \%$, a rate more than three times higher than the general population, with 7,262,734 (2.2\%) Americans infected by COVID-19 (NY Times COVID Data, 2021) among the 332.6M Americans estimated by the U.S. Census Bureau (U.S. Census, 4/1/20). Though our study was not designed to estimate increased risk of infection among individuals with schizophrenia, elevated risk of infection among individuals with schizophrenia has been reported by others [11-13]. Our results focus on identifying risk factors for infection and are consistent with prior research indicating that demographic characteristics[11, 14-15], social determinants[11, 16, 14, 17], psychiatric comorbidities[7, 11], and treatment[18-19] were associated with risk of COVID-19 infection.

Among our study population, social determinants of health were significant contributors to individual risk of infection, with higher rates realized by individuals insured by Medicaid or who lived in counties with higher proportions of African American or Hispanic residents and higher rates among individuals residing in higher income areas. We identified three studies in general populations that reported similar results. In a retrospective 
analysis of COVID-19 infection among 34,503 individuals who sought care at a single regional health system, Rozenfeld[14] reported adjusted odds ratios of 1.51 for African Americans and 2.07 among individuals of Latino ethnicity. Lan[16] reported COVID-19 incidence rate ratios of 2.78 and 2.41 among African American and Hispanic healthcare workers, compared to non-Hispanic white colleagues and in a state-level analysis,

Padalabalanarayanan[17] estimated 4.6\% more COVID-19 cases for each percent increase in a state's African American population. In one of the only other studies to report on individuals with schizophrenia, Wang[11] reported an adjusted odds of infection of 2.3 among African Americans (compared to Caucasians) with schizophrenia. The consistently elevated risk of infection among African Americans and individuals in lowincome household is particularly concerning because these populations are at increased risk for poorer outcomes following COVID-19 infection [11, 20-21].

Further, after accounting for demographic and social determinants, comorbid depressive disorder, bipolar disorder, adjustment disorder, anxiety, and sleep-wake disorders were each independently associated with increased risk of COVID-19 infection. This is consistent with the findings of Taquet[13], who reported that the hazard ratio for a diagnosis of COVID-19 infection was greatest for anxiety disorders, insomnia, and dementia and with those of Wang[11], who reported elevated adjusted odds of COVID-19 infection among individuals with ADHD (adjusted OR: 7.3), bipolar disorder (OR: 7.7), depression (OR: 10.4), and schizophrenia (OR: 9.9).

In contrast, a diagnosis of either alcohol use disorder or post-traumatic stress disorder (PTSD) was associated with lower odds of COVID-19 infection. These results are consistent with those of Yazdi et al.[22], who reported that $43 \%$ of alcohol use disorder patients lived alone during the pandemic, which likely reduced social interactions, leading to a decreased infection risk. Further, in a Veterans Health Administration study, Haderlein et al.[23] reported that veterans with clinically diagnosed PTSD were more likely to receive a COVID-19 test than those without a PTSD diagnosis; these patients were also less likely to test positive for COVID-19.

Consistent with the increased risk among older adults, individuals with higher comorbidity burden were also at increased risk of infection. This may be a consequence of poorer health, compromised immune function, greater healthcare needs, and the inability to maintain physical distancing[21]. Bitan et al.[8] reported that physical health comorbidities were associated with higher COVID-19 mortality rates, as schizophrenia patients were more likely to be obese, smoke, and be diagnosed with diabetes and COPD.

Among the most striking results, individuals with schizophrenia who were actively receiving mental health care in the three months prior to March 2020 had dramatically lower risk of COVID-19 infection. Individuals with a recent, pre-pandemic psychiatry visit, psychotherapy session or community mental health center visit were substantially less likely to receive a COVID-19 diagnosis. These results suggest that active management of schizophrenia reduces the behaviors that lead to exposure and improves patient awareness of the risks associated with COVID-19[24].

Though the inverse association between COVID-19 infection and antipsychotic medication use documented in our study may also represent the value of active therapeutic management, other research conducted to date has yielded inconsistent and conflicting results about the association between antipsychotic treatment and COVID-19 infection risk. Recently published studies have documented both an increased risk of infection[19] and a decreased risk of infection among patients on antipsychotics[18]. The inflammatory mechanisms involved in psychiatric illness and COVID-19 infection in combination with the anti-inflammatory and antiviral effects of antipsychotics appear to be a key driver of the ongoing research[25]. As an example, Crespo-Facorro[26] reported 
that aripiprazole and COVID-19 modulate the expression of genes that modulate immune and inflammatory response at a rate substantially higher than expected.

\section{Strengths and Limitations}

The study included several strengths and limitations. The primary strength is that the study population of 493,796 individuals, represents a substantial proportion of all individuals with diagnosed schizophrenia in the United States, increasing the generalizability of results. Second, the population included individuals across a spectrum of ages, insurance types, and geographic regions. Third, the study included both healthcare utilization and social determinants of health data. The most significant limitation is the open dataset, which does not include insurance eligibility information and thus may result in incomplete ascertainment of healthcare utilization. The second substantive limitation is that social determinants are measured at the county, rather than individual, level and thus may not represent an individual's specific situation. Finally, the dataset includes neither symptom severity nor mortality information.

\section{Conclusions}

In the general U.S. population, individuals diagnosed with schizophrenia were at significantly higher risk of COVID-19 infection and our study suggests that risk was elevated further among the underserved, among African Americans and the Hispanic population, and among those with psychiatric comorbidity. The protective effect of psychiatric care and of antipsychotic medication use underscored the importance of continual care throughout the pandemic.

\section{Abbreviations}

\begin{tabular}{|ll|}
\hline Abbreviation & Description \\
\hline $\mathrm{Cl}$ & Confidence Interval \\
$\mathrm{CMHC}$ & Community Mental Health Center \\
COPD & Chronic Obstructive Pulmonary Disease \\
\hline ICD-10 & International Classification of Diseases, Tenth Revision \\
LAI & Long-Acting Injectible \\
\hline OR & Odd Ratio \\
\hline PTSD & Post Traumatic Stress Disorder \\
\hline SD & Standard Deviation \\
\hline
\end{tabular}

\section{Declarations}

\section{Ethics Approval and Consent to Participate:}


The study protocol including use of the Clarivate claims dataset was reviewed by the Advarra Institutional Review Board (IRB) and was determined to be exempt from broad IRB approval, as this research study did not qualify as human subjects research. All data were de-identified and HIPAA compliant, and all methods were performed in accordance with the relevant guidelines and regulations.

\section{Consent for Publication:}

Not applicable.

\section{Availability of Data and Materials:}

The administrative medical and pharmacy claims data that support the findings of this study are available from Clarivate (https://clarivate.com) but restrictions apply to the availability of these data, which were used under license for the current study, and so are not publicly available. Data are however available from the authors upon reasonable request and with permission of Clarivate. The social determinants of health data are publicly available as part of the Area Health Resources Files, available at https://data.hrsa.gov/topics/healthworkforce/ahrf.

\section{Competing Interests:}

Drs. Pesa and Petrillo are employees of Janssen Scientific Affairs. Drs. Liberman and Ruetsch are employees of Health Analytics, LLC which was funded to conduct the study.

\section{Funding Source:}

This study was funded by Janssen Scientific Affairs.

\section{Author Contributions:}

Project conception (JNL); design of the work (JNL, JP, MPP, CR); analysis (JNL); interpretation (JNL, JP, MPP, CR); writing or editing (JNL, MP, MPP, CR).

\section{Acknowledgements:}

The authors wish to thank Pei Liu for statistical analysis support.

\section{References}

1. Owen MJ, Sawa A, Mortensen PB. Schizophrenia. Lancet. 2016 Jul 2;388(10039):86-97. doi: 10.1016/S01406736(15)01121-6. Epub 2016 Jan 15. PMID: 26777917; PMCID: PMC4940219. 
2. McGrath J, Saha S, Chant D, Welham J. Schizophrenia: a concise overview of incidence, prevalence, and mortality. Epidemiol Rev. 2008;30:67-76. doi: 10.1093/epirev/mxn001. epub 2008 May 14. PMID: 18480098.

3. Simeone, J. C., Ward, A. J., Rotella, P., Collins, J., \& Windisch, R. (2015). An evaluation of variation in published estimates of schizophrenia prevalence from 1990-2013: a systematic literature review. BMC Psychiatry, 15, 193. https://doi.org/10.1186/s12888-015-0578-7.

4. Wu EQ, Shi L, Birnbaum H, Hudson T, Kessler R. Annual prevalence of diagnosed schizophrenia in the USA: a claims data analysis approach. Psychological Medicine 2006;36:1535-1540.

5. Nasrallah HA, Meyer JM, Goff DC, McEvoy JP, Davis SM, Stroup TS, Lieberman JA. Low rates of treatment for hypertension, dyslipidemia and diabetes in schizophrenia: Data from the CATI schizophrenia trial sample at baseline. Schizophrenia Research 2006;86(1-3):15-22.

6. Kozloff N, Mulsant b, Stergiopoulos V, Voinekos A. The COVID-19 Global Pandemic: Implications for People with Schizophrenia and Related Disorders. Schizophr Bull 2020. doi: https://doi.org/10.1093/schbul/sbaa051

7. Yang $\mathrm{H}$, Chen W, Hu W, et al. Pre-pandemic psychiatric disorders and risk COVID-19: a UK Biobank cohort analysis. Lancet Healthy Longev 2020;1:e69-79. https://doi.org/10.1016/S2666-7568*20)30013-1

8. Bitan DT, Krieger I, Kridin K, et al. COVID-19 prevalence and mortality among schizophrenia patients: A largescale retrospective cohort study. Schizophr Bull 2021;sbab012. doi: 10.1093/schbul/sbab012. Epub ahead of print.

9. Nemani K, Li C, Olfson M, Blessing EM, Razavian N, Chen J, Petkova E, Goff DC. Association of psychiatric disorders with mortality among patients with COVID-19. JAMA Psychiatry 2021;78(4):380-386.

10. Charlson ME, Pompei P, Ales KL, Mackenzie CR. A new method of classifying prognostic comorbidity in longitudinal studies: Develop and validation. J Chron Dis 1987;40(5):373-383.

11. Wang Q, Xu R, Vokow ND. Increased risk of COVID-19 infection and mortality in people with mental disorders: analysis from electronic health records in the United States. World Psychiatry 2021;20:124-130.

12. Ji W, Huh K, Kang M, Hong J, Bae GH, Lee R, Na Y, Choi H, Gong SY, Choi Y-H, Ko K-P, Im J-S, Jung J. Effect of underlying comorbidities on the infection and severity of COVID-19 in Korea: a nationwide case-control study. J Korean Med Sci 2020;35:e237. Doi: 10.3346/jkms.2020.35.3237.

13. Taquet, M., Luciano, S., Geddes, J. R., \& Harrison, P. J. (2021). Bidirectional associations between COVID-19 and psychiatric disorder: retrospective cohort studies of 62,354 COVID-19 cases in the USA. The Lancet Psychiatry, 8(2), 130-140.

14. Rozenfeld Y, Beam J, Maier H, Haggerson W, Boudreau K, Carlson J, Medows R. A model of disparities: risk factors associated with COVID-19 infection. Int J Equity Health 2020;19:126.

15. Liu T, Liang W, Zhong H, He J, Chen Z, He G, Song T, Chen S, Wang P, Li J, Lan Y, Cheng M, Huang J, Niu J, Xia L, Xiao J, Hu J, Lin L, Huang Q, Rong Z, Deng A, Zeng W, Li J, Li X, Tan X, Kang M, Guo L, Zhu Z, Gong D, Chen G, Dong M, \& Ma W. Risk factors associated with COVID-19 infection: a retrospective cohort study based on contacts tracing. Emerg Microbes Infect 2020;9*1,1546-1553, doi: 10.1080/22221751.2020.1787799.

16. Lan F-Y, Filler R, Mathew S, Buley J, Eiliaki E, Bruno-Murtha LA, Osgood R, Christophi CA, Fernandez-Montero A, Kales SN. Sociodemographic risk factors for coronavirus disease 2019 (COVID-19) infection among Massachusetts healthcare workers: A retrospective cohort study. Infect Control \& Hosp Epidemiol, https://doi.org/10.1017/ice.2021.17. 
17. Padalabalanarayanan S, Hanumanthu VS, Sen B. Association of state stay-at-home orders and state-level African American population with COVID-19 case rates. JAMA Netw Open 2020;3(10):e2026010. doi:10.1001/jamanetworkopen.2020.26010

18. Canal-Rivero M, Catalan-Barragan R, Rubio-Garcia A, Garrido-Torres N, Crespo-Facorro B, Ruiz-Veguilla M, and IBIS Translational Psychiatry Group. Lower risk of SARS-CoV2 infection in individuals with severe mental disorders on antipsychotic treatment: A retrospective epidemiological study in a representative Spanish population. Schizophr Res 2021;229:53-54: doi: 10.1016/j.schres.2021.02.002.

19. Govind R, Fonseca de Freitas D, Pritchard M, Hayes RD, MacCabe JH. Clozapine treatment and risk of COVID-19 infection: retrospective cohort study. Br J Psych (2021);219:368-374. doi: 10.1192/bjp.2020.151

20. Azar KMJ, Shen Z, Romanelli RJ, Lockhart SH, Smits K, Robinson S, Brown S, Pressman AR. Disparities in outcomes among COVID-19 patients in a large health care system in California. Health Affairs 2020;39:7:1253-1262. doi: 10.1377/hlthaff.2020.00598.

21. Raifman MA, Raifman JR. Disparities in the population at risk of severe illness from COVID-19 by race/ethnicity and income. Am J Prevent Med 2020;59(1):137-139.

22. Yazdi K, Fuchs-Leitner I, Rosenleitner J, Gerstgrasser NW. Impact of the COVID-19 Pandemic on Patients With Alcohol Use Disorder and Associated Risk Factors for Relapse. Frontiers in Psychiatry 2020, 11.

23. Haderlein TP, Wong MS, Yua A, Llorente MD, Washington DL (2020). Association of PTSD with COVID-19 testing and infection in the Veterans Health Administration. J Psychiatr Res 2020;S0022-3956(20)31092-X. doi: 10.1016/j.jpsychires.2020.11.033

24. Kahl KG, Correll CU. Management of patients with severe mental illness during the coronavirus disease 2019 pandemic. JAMA Psychiatry Sept. 2020;77(9).

25. Tendilla-Beltran H, Flores G. Due to their anti-inflammatory, antioxidant and neurotrophic properties, secondgeneration antipsychotics are suitable in patients with schizophrenia and COVID-19. Gen Hosp Psychiatry 2021;71:137-139. Doi: 10.1016/j.genhosppsych.2021.05.005.

26. Crespo-Facorro B, Ruiz-Veguilla M, Vazques-Bourgon J, et al. Aripiprazole as a candidate treatment of COVID-19 identified through genomic analysis. Front Pharmacol 2021;

https://doi.org/10.3389/fphar.2021.646701

\section{Tables}


Table 1

Flow Diagram for the Selection of Eligible Participants

$\begin{array}{lll}\text { Step Inclusion/Exclusion } & \begin{array}{l}\text { Retained } \\ \text { Cases }\end{array} & \text { Retained }\end{array}$

$1 \quad \geq 2$ diagnosis codes of schizophrenia from outpatient claims (at least one with schizophrenia diagnosis in primary position) OR one inpatient $\quad 710,948$ claim with schizophrenia in the primary position during the period January 1, 2019 through June 30, 2020.

\begin{tabular}{|l|lr}
\hline 2 & 18 years of age or older as of January 1, 2019 & $99.1 \%$ \\
\hline 3 & $\begin{array}{l}\text { At least one medical or Rx claim in the first half of } 2019 \text { (Jan. Jun.) and } \\
\text { at least one in the first half of } 2020 \text { (Jan. Jun.) }\end{array}$ & 579,820 \\
\hline 4 & Patients in 50 states and DC & $57.6 \%$ \\
\hline 5 & 1+ Med or Rx claim in Q3, 2020 & $41.3 \%$ \\
\hline
\end{tabular}


Table 2

Select Demographic Characteristics

Received COVID-19 Diagnosis

\begin{tabular}{lclllll}
\multicolumn{2}{l}{ Total Population } & No & \multicolumn{3}{c}{ Yes } \\
$\mathrm{N}=$ & 493796 & $\mathrm{~N}=$ & 458547 & $\mathrm{~N}=$ & 35249 & \\
$\mathrm{n} /($ mean) & $\% /(\mathrm{SD})$ & $\mathrm{n} /($ mean) & $\% /(\mathrm{SD})$ & $\mathrm{n} /($ mean $)$ & $\% /(\mathrm{SD})$ & $\begin{array}{l}\mathrm{p}- \\
\text { value }\end{array}$
\end{tabular}

\section{Demographics}

Gender

\begin{tabular}{llllllll} 
Female & 221,217 & $44.8 \%$ & 203,330 & $44.3 \%$ & 17,887 & $50.7 \%$ & $<0.001$ \\
Male & 272,369 & $55.2 \%$ & 255,007 & $55.6 \%$ & 17,362 & $49.3 \%$ \\
\hline Unknown & 210 & $0.0 \%$ & 210 & $0.0 \%$ & 0 & $0.0 \%$
\end{tabular}

Age

\begin{tabular}{llllllll}
\hline $18-30$ & 66,513 & $13.5 \%$ & 64,553 & $14.0 \%$ & 1,960 & $5.6 \%$ & $<0.001$ \\
\hline $31-49$ & 158,898 & $32.3 \%$ & 153,186 & $33.4 \%$ & 5,712 & $16.2 \%$ & \\
\hline $50-64$ & 176,889 & $35.8 \%$ & 164,453 & $35.9 \%$ & 12,436 & $35.3 \%$ & \\
\hline Over 65 & 91,496 & $18.5 \%$ & 76,355 & $16.7 \%$ & 15,141 & $43.0 \%$
\end{tabular}

Insurance

\begin{tabular}{llllllll} 
Commercial & 66,630 & $13.5 \%$ & 64,850 & $14.1 \%$ & 1,780 & $5.0 \%$ & $<0.001$ \\
\hline Medicaid & 336,542 & $68.2 \%$ & 308,080 & $67.2 \%$ & 28,462 & $80.7 \%$ & \\
\hline Medicare & 89,676 & $18.2 \%$ & 84,766 & $18.5 \%$ & 5,001 & $14.2 \%$ & $0.0 \%$ \\
\hline VA/Other & 857 & $0.2 \%$ & 851 & $0.2 \%$ & 6 &
\end{tabular}

\section{Social Determinants}

Income (median household (60.43)

income)
(15.79) (60.37)
(15.77)
(61.24)
$(15.98)<0.001$

Education

$\%$ graduated

high school

(87.0)

(5.3)

(87.1)

(5.3)

(86.5)

$(5.4) \quad<0.001$ 
Race
African
American/Black
(16.0)
(14.1)
(16)
(14.1)
(16.6)
(13.6) $<0.001$
(\%)
White (\%)
(59.1)
(22.2)
(59.3)
(22.2)
(56.6)
$(22.2) \quad<0.001$
Asian (\%)
(5.7)
(6.1)
(5.7)
(6)
(6.2)
(6.4) $<0.001$

Ethnicity

Hispanic (\%)

(16.4)

(15.9)

(16.3)

(15.9)

(18.1)

$(16.6) \quad<0.001$

Population Density (000s

per sq mile)

(3664)

(9914) (3637)

(9993)

(3550)

$(8831)<0.05$
Charlson Comorbidity Index (1.3)

(1.9)

(1.2)

(1.8)

(2.5)

(2.4) $\quad<0.001$

Behavioral, Psychiatric

Comorbidities

\begin{tabular}{lccccccc} 
Anxiety disorder & 155,636 & $31.5 \%$ & 140,723 & $30.7 \%$ & 14,913 & $42.3 \%$ & $<0.001$ \\
\hline $\begin{array}{l}\text { Depressive } \\
\text { disorders: MDD, } \\
\text { dysthymia }\end{array}$ & 146,549 & $29.7 \%$ & 130,338 & $28.4 \%$ & 16,256 & $46.1 \%$ & $<0.001$ \\
$\begin{array}{l}\text { Bipolar } \\
\text { depression }\end{array}$ & 121,164 & $24.5 \%$ & 110,097 & $24.0 \%$ & 11,067 & $31.4 \%$ & $<0.001$ \\
\hline $\begin{array}{l}\text { Sleep-wake } \\
\text { disorder }\end{array}$ & 82,560 & $16.7 \%$ & 73,975 & $16.1 \%$ & 8,585 & $24.4 \%$ & $<0.001$ \\
\hline $\begin{array}{l}\text { Alcohol Use } \\
\text { disorder }\end{array}$ & 59,207 & $12.0 \%$ & 55,273 & $12.1 \%$ & 3,934 & $11.2 \%$ & $<0.001$ \\
$\begin{array}{l}\text { Post-traumatic } \\
\text { stress disorder }\end{array}$ & 45,473 & $9.2 \%$ & 43,023 & $9.4 \%$ & 2,450 & $7.0 \%$ & $<0.001$ \\
\hline $\begin{array}{l}\text { Adjustment } \\
\text { disorders }\end{array}$ & 16,879 & $3.4 \%$ & 14,948 & $3.3 \%$ & 1,931 & $5.5 \%$ & $<0.001$ \\
\hline $\begin{array}{l}\text { Obsessive } \\
\text { compulsive } \\
\text { disorders }\end{array}$ & 10,817 & $2.2 \%$ & 10,012 & $2.2 \%$ & 805 & $2.3 \%$ & $\mathrm{NS}$ \\
\hline
\end{tabular}

Baseline Treatment History

\begin{tabular}{lccccccc}
$\begin{array}{l}\text { Psychiatric visit } \\
\text { (yes) }\end{array}$ & 41,060 & $8.3 \%$ & 39,733 & $8.7 \%$ & 1,327 & $3.8 \%$ & $<0.001$ \\
\hline Psychotherapy & 30,290 & $6.1 \%$ & $\begin{array}{c}29,237 \\
\text { Page } 13 / 17\end{array}$ & $6.4 \%$ & 1,053 & $3.0 \%$ & $<0.001$
\end{tabular}




\begin{tabular}{llllllll}
\hline visit (yes) & \multicolumn{2}{l}{0} & & & \\
\hline LAl use (yes) & 32,338 & $6.5 \%$ & 31,224 & $6.8 \%$ & 1,114 & $3.2 \%$ & $<0.01$ \\
\hline $\begin{array}{l}\text { Oral } \\
\text { antipsychotic } \\
\text { use (yes) }\end{array}$ & 122,361 & $24.8 \%$ & 117,013 & $25.5 \%$ & 5,384 & $15.2 \%$ & $<0.001$ \\
\hline $\begin{array}{l}\text { CMHC visit } \\
\text { (yes) }\end{array}$ & 43,741 & $8.9 \%$ & 42,410 & $9.2 \%$ & 1,331 & $3.8 \%$ & $<0.001$ \\
\hline $\begin{array}{l}\text { Partial-day } \\
\text { hospitalization } \\
\text { visit (yes) }\end{array}$ & 2,176 & $0.4 \%$ & 2,052 & $0.5 \%$ & 124 & $0.4 \%$ & $<0.01$ \\
\hline $\begin{array}{l}\text { Schizophrenia- } \\
\text { specific } \\
\text { hospitalization } \\
\text { (yes) }\end{array}$ & 17,255 & $3.5 \%$ & 15,982 & $3.5 \%$ & 1,273 & $3.6 \%$ & NS \\
\hline $\begin{array}{l}\text { Schizophrenia- } \\
\text { specific ED visit } \\
\text { (yes) }\end{array}$ & 9,196 & $1.9 \%$ & 8,485 & $1.9 \%$ & 711 & $2.0 \%$ & $<0.05$ \\
\hline
\end{tabular}


Table 3

Adjusted Odds of COVID-19 Infection among Individuals with Schizophrenia

\begin{tabular}{|c|c|c|c|c|}
\hline Variable & Level & Odds & Lower & Upper \\
\hline \multirow[t]{7}{*}{ Age } & $80+$ years & 5.92 & 5.51 & 6.35 \\
\hline & $70-79$ years & 4.44 & 4.19 & 4.71 \\
\hline & $60-69$ years & 2.65 & 2.51 & 2.80 \\
\hline & $50-59$ years & 1.56 & 1.48 & 1.65 \\
\hline & $40-49$ years & 1.16 & 1.09 & 1.23 \\
\hline & $30-39$ years & NS & & \\
\hline & $18-29$ years & 1.00 & & \\
\hline \multirow[t]{2}{*}{ Sex } & Male & 1.08 & 1.05 & 1.10 \\
\hline & Female & 1.00 & & \\
\hline \multirow[t]{4}{*}{ Insurer } & VA/Other & 0.41 & 0.18 & 0.91 \\
\hline & Medicare & 1.23 & 1.16 & 1.30 \\
\hline & Medicaid & 2.17 & 2.07 & 2.28 \\
\hline & Commercial & 1.00 & & \\
\hline \multirow[t]{3}{*}{ Rural } & Rural & NS & NS & NS \\
\hline & Urban & 0.94 & 0.90 & 0.99 \\
\hline & Metro & 1.00 & & \\
\hline \multirow[t]{5}{*}{ Household Income } & Highest quintile & 1.17 & 1.11 & 1.23 \\
\hline & 4th quintile & 1.15 & 1.10 & 1.20 \\
\hline & 3rd quintile & 1.05 & 1.01 & 1.09 \\
\hline & 2nd quintile & NS & NS & NS \\
\hline & Lowest quintile & 1.00 & & \\
\hline Black/African American (\%) & Highest quintile & 1.42 & 1.35 & 1.49 \\
\hline
\end{tabular}




\begin{tabular}{|c|c|c|c|c|}
\hline & 4th quintile & 1.26 & 1.20 & 1.32 \\
\hline & 3rd quintile & 1.39 & 1.33 & 1.46 \\
\hline & 2nd quintile & 1.20 & 1.15 & 1.26 \\
\hline & Lowest quintile & 1.00 & & \\
\hline \multirow[t]{5}{*}{ Asian (\%) } & Highest quintile & 0.83 & 0.78 & 0.88 \\
\hline & 4th quintile & NS & NS & NS \\
\hline & 3rd quintile & 0.84 & 0.80 & 0.88 \\
\hline & 2nd quintile & 0.87 & 0.83 & 0.92 \\
\hline & Lowest quintile & 1.00 & & \\
\hline \multirow[t]{5}{*}{ Hispanic (\%) } & Highest quintile & 1.23 & 1.17 & 1.28 \\
\hline & 4th quintile & 1.23 & 1.18 & 1.28 \\
\hline & 3rd quintile & 0.90 & 0.87 & 0.94 \\
\hline & 2nd quintile & 0.96 & 0.92 & 1.00 \\
\hline & Lowest quintile & 1.00 & & \\
\hline \multirow[t]{4}{*}{ Charlson Comorbidity Index } & $5+$ & 2.76 & 2.65 & 2.87 \\
\hline & $3-4$ & 2.53 & 2.44 & 2.63 \\
\hline & $1-2$ & 1.84 & 1.78 & 1.90 \\
\hline & 0 & 1.00 & & \\
\hline \multirow[t]{7}{*}{ Psychiatric Comorbidities } & Depressive disorder & 1.45 & 1.41 & 1.49 \\
\hline & Adjustment disorder & 1.29 & 1.23 & 1.36 \\
\hline & Bipolar & 1.22 & 1.19 & 1.25 \\
\hline & Anxiety & 1.23 & 1.20 & 1.26 \\
\hline & Sleep wake disorder & 1.16 & 1.13 & 1.19 \\
\hline & Alcohol use disorder & 0.86 & 0.82 & 0.89 \\
\hline & PTSD & 0.79 & 0.75 & 0.82 \\
\hline \multirow[t]{2}{*}{ Psychiatric Care } & Psychiatry visit (pre-pandemic) & 0.56 & 0.53 & 0.59 \\
\hline & $\begin{array}{c}\text { CMHC visit (pre-pandemic) } \\
\text { Page } 16 / 17\end{array}$ & 0.55 & 0.52 & 0.58 \\
\hline
\end{tabular}




\begin{tabular}{llll} 
LAl use (yes) & 0.72 & 0.68 & 0.77 \\
\hline Oral antipsychotic use (yes) & 0.62 & 0.60 & 0.64
\end{tabular}

\section{Figures}

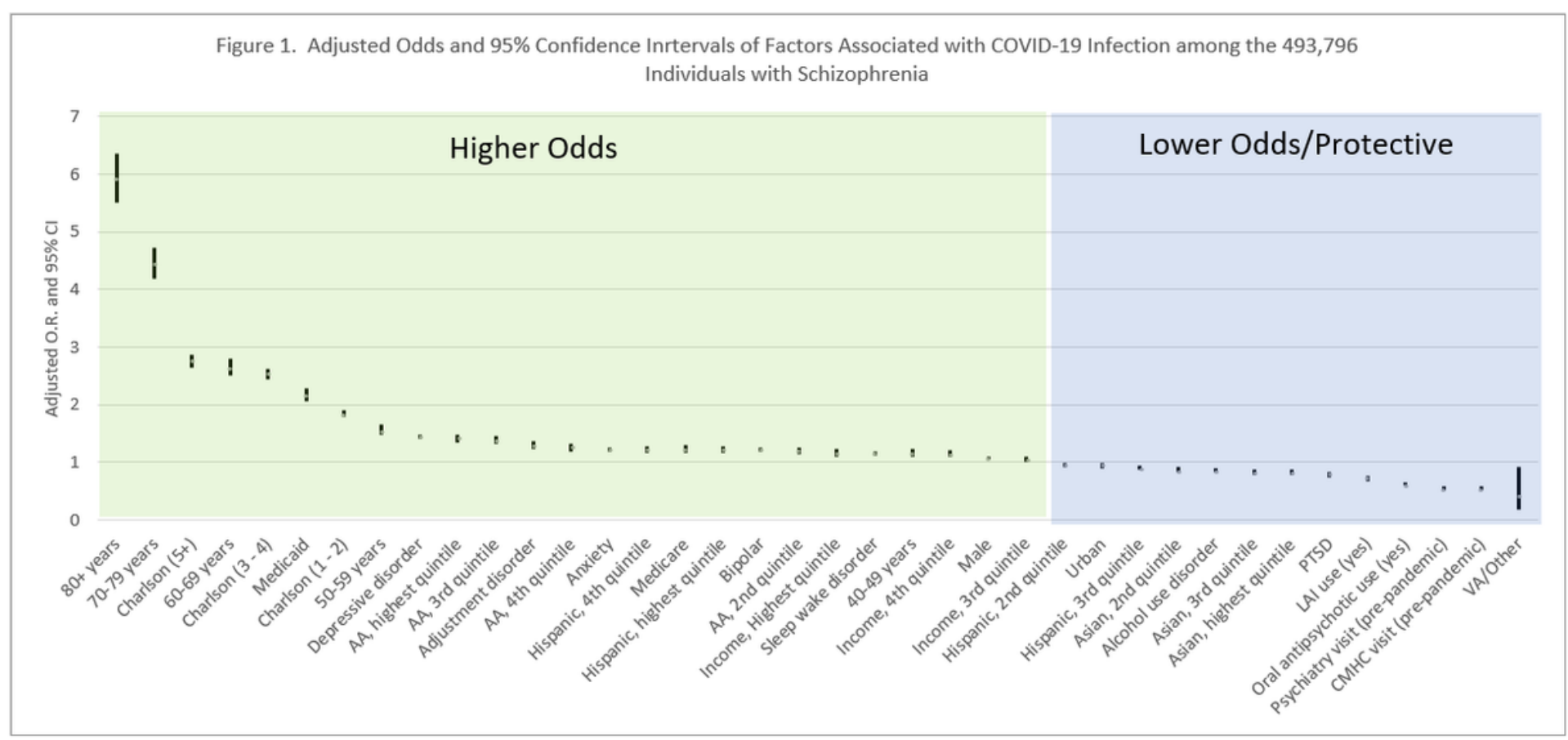

\section{Figure 1}

Please See image above for figure legend. 